A. Sakultantimetha, ${ }^{1}$ H. E. Keenan, ${ }^{1}$ M. Dyer, ${ }^{2}$ T. K. Beattie, ${ }^{1}$ S. Bangkedphol, ${ }^{1}$ and A. Songsasen ${ }^{3}$

\title{
Isolation of Tributyltin-Degrading Bacteria Citrobacter braakii and Enterobacter cloacae from Butyltin-Polluted Sediment
}

\begin{abstract}
Tributyltin compound (TBT) released into the aquatic environment is generally degraded by bacteria in water and sediment. The isolation of TBT-degrading bacteria from TBT polluted sediment leads to the indication of specific potential TBT degraders. Two new strains of bacteria designated as B2 and B3 were successfully isolated using glycerol medium containing tributyltin chloride (TBTC) at $130 \mu M$ from contaminated sediment collected from Bowling Basin in Glasgow. The observed degradation after 14 days of the microcosm from the sediment and the isolated bacteria were investigated at an initial concentration of $1 \mu M$ TBTC. It was found that TBT was degraded by the bacterial strains B2 and B3 at 8.3 and $16.9 \%$, respectively. The results indicate that $\mathrm{B} 2$ and $\mathrm{B} 3$ are effective as TBT degraders. $\mathrm{EC}_{50}$ of $\mathrm{B} 2$ and $\mathrm{B} 3$ in water were 88.73 and $112.53 \mu M$ TBTC, which were significantly higher than the concentration of TBT measured at the basin, suggesting a low effect of TBT on the growth and activity of bacteria. After identification using API 20E and 16S sequencing, the bacterial isolate strain B2 is Citrobacter braakii and B3 is Enterobacter cloacae. Therefore, this study has discovered two species of high resistance TBT degrader which have never been previously studied or isolated based upon TBT degradation ability.
\end{abstract}

KEYWORDS: tributyltin, isolation, degradation, Citrobacter braakii, Enterobacter cloacae

\section{Introduction}

Tributyltin is one of the most toxic compounds widely used as antifouling paint and wood preservative due to its biocidal property. Trade names include Biomet, Antifouling Alusea, Antifouling Seamate, C-clean 6000, Intersmooth, Hempel's Antifouling Nautic, and Sigmaplane [1]. The usage of TBT and its derivatives has drawn concern about the potential damage to the aquatic environment.

Of particular significance, TBT is toxic to nontarget organisms at low concentration (ppt) [2]. It is also an endocrine disruptor which interferes with the endocrine system in organisms and humans [3]. It causes physical damage, reproductive effects, immunological effects, and imposex, and it is still uncertain if it is a carcinogen [4]. Legislation and a ban on the use of TBT was brought in globally concern due to its toxicity. TBT has been classed as a Persistent Organic Pollutant (POP) but an enormous amount of this compound has already been introduced to the terrestrial and aquatic environment [5]. The accumulation of TBT in environmental media and organism's tissue has become an important issue particularly as it can be biomagnified in the food chain and impacts greatly upon the highest level predator, humans.

However, TBT can break down and produce dibutyltin (DBT) and monobutyltin (MBT) by debutylation, which reduces its toxicity. The process can be via physicochemical mechanisms including hydrolysis, photodegradation, and chemical cleavage. Biodegradation is also an effective process which leads to the sustainable remediation, utilizing microorganisms under the control of suitable parameters. Biodegradation can be used to limit the level of TBT to a concentration that does not cause an impact on living organisms and the environment and which is below the environmental quality standard.

Even though the environment can self-recover from TBT contamination by indigenous microbes, the 
process can be slow without intervention [6]. Understanding of the degradation process has led to improvement and encouragement of TBT remediation. The objective of this study is to obtain a bacterium which consistently shows efficiency in TBT degradation under the conditions specified. The isolate identified could then be used as a degradation enhancement by bioaugmentation which provides a quick start for the remediation treatment. In this paper, bacteria in contaminated sediment collected from the aquatic environment in Glasgow was isolated, identified, and investigated experimentally to determine its ability as a TBT degrader, and also intends to provide preliminary information for the further improvement of remediation using these isolated bacteria.

\section{Materials and Methods}

\section{Chemicals}

All chemicals were used without additional purification. TBT chloride (96\% purity), DBT chloride (98\% purity), MBT chloride (95\% purity), tropolone (98\% purity), and hexylmagnesium bromide solution ( $2 M$ in diethyl ether) were obtained from Aldrich (Steinheim, Germany). All solvents were liquid chromatography grade obtained from Merck (Darmstadt, Germany). All bacteriological nutrients and agars were obtained from Oxoid (Basingstoke, U.K.). All other chemicals used were of analytical grade.

\section{Sample Collection}

The sediment and water samples were collected from Bowling Basin, Glasgow, UK (NS 450 735) in March 2007. The basin is part of the Forth and Clyde canal system which was a main Scottish waterway. The water samples were stored in autoclaved polypropylene bottles to determine butyltin contamination levels in water. The surface layer sediment samples were taken using a dredge sampler at $15 \mathrm{~cm}$ in depth. Sediment samples were divided into two subsamples for determination of butyltins concentration and for microcosm experiments. All of the sediments were stored in autoclaved polypropylene bottles. Samples were kept at $4^{\circ} \mathrm{C}$ in the dark. The analysis and microcosm experiments were performed immediately after sampling.

Butyltin compounds in the sediment and water were extracted and analyzed following the procedures reported previously [7]. The moisture content and total organic carbon of the sediment was examined based on ASTM standard D2974-87 [8].

\section{Isolation of TBT-Degrading Bacteria}

The liquid glycerol medium used for isolation (1 L) was made up of $1 \mathrm{~g}$ of dipotassium hydrogen phosphate, $1 \mathrm{~g}$ of potassium dihydrogen phosphate, $1 \mathrm{~g}$ of ammonium sulfate, $0.4 \mathrm{~g}$ of magnesium chloride, $0.5 \mathrm{~g}$ of yeast extract, and $1 \mathrm{~mL}$ of glycerol and adjusted to $\mathrm{pH} 6.8$ by adding the required volume of $2 \mathrm{~N} \mathrm{NaOH}$ prior to sterilization. To prepare the screening medium, the TBTC stock solution of $13 \mathrm{mM}$ in methanol was added into the glycerol medium to give a final concentration of $130 \mu M$ TBTC. A $10 \mathrm{~g}$ amount of the sediment was added to $100 \mathrm{~mL}$ of the screening medium and mixed. A $10 \mathrm{~mL}$ aliquot of supernatant was subsequently transferred into fresh medium, followed by incubation at $28^{\circ} \mathrm{C}$ and shaking at $150 \mathrm{rpm}$. After 10 days of incubation, a $4 \mathrm{~mL}$ aliquot of supernatant was inoculated into a fresh screening medium. After subculturing four times, the supernatant was streaked onto a screening medium agar containing $130 \mu M$ TBTC. Single colonies were transferred to fresh media to obtain pure cultures.

\section{Assay for TBT Degradation}

Liquid samples containing TBT were prepared from a $1 \mathrm{~m} M$ TBTC stock solution in methanol. The stock solution was diluted to $1 \mu M$ or $325.5 \mathrm{ppb}$ TBTC in sterile glycerol medium. The bacterial isolates from previous isolation were cultured in the glycerol medium without TBTC at $28^{\circ} \mathrm{C}$ for $24 \mathrm{~h}$. Each bacterial culture was transferred to the study solution at a volume ratio of 5:100. Two controls were performed on the samples by (1) using the medium containing TBT but without bacterial cells to observe any potential photo- and chemical degradation, and (2) the cultures were grown in the medium without TBT, and TBT was then added before analysis to examine adsorption of TBT on bacterial cells. After mixing, samples 
were immediately placed into an incubator at $28^{\circ} \mathrm{C}$ and continuously shaken at $150 \mathrm{rpm}$. After 14 days of incubation, the samples were analyzed for butyltins. The degradation was compared under the specific conditions.

\section{Analysis of Butyltin Compounds}

All samples were sonicated for $30 \mathrm{~min}$. From each sample, a $50 \mathrm{~mL}$ aliquot of the solution was withdrawn and an internal standard, tetrabutyltin chloride in methanol, was added to a concentration of $200 \mathrm{ppb}$. Extraction followed the method described by Bangkedphol [7]. The sample vial was purged with nitrogen gas to achieve an inert atmosphere chamber to exclude oxygen and water. A $0.2 \mathrm{~mL}$ solution of $2 M$ $n$-hexylmagnesium bromide was added and derivatized for $30 \mathrm{~min}$. The reaction was stopped by adding 2 $\mathrm{mL}$ of $2 \mathrm{M} \mathrm{HCl}$ and the solution was set aside for $30 \mathrm{~min}$. The organic phase was separated and moisture was removed with anhydrous ammonium sulfate. The derivatized solution $(3 \mu \mathrm{L})$ was injected into a Hewlett-Packard (HP) (Palo Alto, CA) Model 5980 gas chromatograph (GC) attached to a 5989B mass spectrometer (MS). The chromatographic capillary column was an HP5, $30 \mathrm{~m}$ by $0.25-\mathrm{m}$ inside diameter, $0.25 \mu \mathrm{m}$ film thickness. The carrier gas was helium with a flow rate of $1 \mathrm{~mL} / \mathrm{min}$. Injector and detector temperatures were held at $280^{\circ} \mathrm{C}$ and $300^{\circ} \mathrm{C}$, respectively. The solvent delay was $8 \mathrm{~min}$. The column oven temperature was programed from an initial temperature of $100^{\circ} \mathrm{C}$, held for $2 \mathrm{~min}$, to a final temperature of $300^{\circ} \mathrm{C}$ at a rate of $15^{\circ} \mathrm{C} / \mathrm{min}$, and held for $10 \mathrm{~min}$. Sample injection was split mode. The MS was full scan in electron ionization mode. The detector acquisition method employed selected ion monitoring for TBT, DBT, and MBT between $m / z 205$ and 390, over total ions. The peak areas and mass spectra (total ion chromatogram) were recorded. The average areas were plotted against solution concentration to form the calibration graph.

\section{Resistance of Heterotrophic Bacteria}

Sterile canal water was prepared as a source of nutrients for this study. The isolated bacteria, B2 and B3, were reinoculated in sterile canal water and incubated at $28^{\circ} \mathrm{C}$ for 7 days to obtain single bacteria enriched solution. A $10 \mathrm{~mL}$ aliquot of each study sample containing TBT was prepared from 1,000 ppm TBTC stock solution in methanol. Stock solution was diluted with the single bacteria enriched solution to make up different concentrations, $0,100,200,400,800$, and 1,000 $\mu M$ TBTC. The study samples were then incubated at $28^{\circ} \mathrm{C}$ for 7 days with shaking at $150 \mathrm{rpm}$. After incubation each study sample was serial diluted and $100 \mu \mathrm{L}$ of each spread over plate count agar which was incubated at $28^{\circ} \mathrm{C}$ overnight. Colony forming units of bacteria were counted to calculate the effective concentration giving $50 \%$ microorganism inhibition $\left(\mathrm{EC}_{50}\right)$ which was carried out following the Reed and Muench [9] method.

\section{Identification and Characterization of TBT-Degrading Bacteria}

The isolated TBT-degrading bacteria were characterized by Gram staining and microscopic examination. Biochemical tests of the isolates were performed using the API 20E system (bioMérieux, Hampshire, U.K.). Additionally, oxidase and catalase tests, were performed according to the manufacturer's recommendations and Bergey's Manual of Systematic Bacteriology [10].

Extraction of chromosomic DNA from the unknown isolates was carried out followed the protocol for E. coli which represents a wide type of Gram negative bacteria [11]. Polymerase chain reaction (PCR) was performed using universal bacteria primers $27 \mathrm{~F}$ ( $5^{\prime}$-AGAGTTTGATCMTGGCTCAG- $\left.3^{\prime}\right)$, where $M$ is A or C, and 1525R (5'-AAGGAGGTGWTCCARCC-3'), where $W$ is A or T, and $R$ is A or G. A $50 \mu \mathrm{L}$ aliquot of PCR reaction system contained $5 \mu \mathrm{L}$ of $10 \times$ buffer, $0.8 \mu \mathrm{L}$ of $10 \mathrm{~m} M \mathrm{dNTPs}, 1.5 \mu \mathrm{L}$ of 50 $\mathrm{mM}$ of $\mathrm{MgCl}_{2}, 0.625 \mu \mathrm{L}$ of $20 \mathrm{~m} M$ of each primer, $0.25 \mu \mathrm{L}$ of $5 \mathrm{U} / \mu \mathrm{L}$ Taq DNA polymerase, and $2 \mu \mathrm{L}$ of DNA. Master Mix was prepared without DNA under cool temperature. Then, $48 \mu \mathrm{L}$ from the Master Mix was transferred into a PCR microfuge tube and mixed with $2 \mu \mathrm{L}$ aliquot of a suitable concentration of DNA. The PCR conditions were as follows: denaturizing at $95^{\circ} \mathrm{C}$ for $5 \mathrm{~min} ; 30$ cycles of denaturation $\left(1 \mathrm{~min}, 95^{\circ} \mathrm{C}\right)$, primer annealing $\left(1 \mathrm{~min}, 52^{\circ} \mathrm{C}\right)$, and primer extension $\left(1 \mathrm{~min}, 72^{\circ} \mathrm{C}\right)$ with a final $10 \mathrm{~min}$ annealing step at $72^{\circ} \mathrm{C}$. The recovered PCR products were sequenced by first base (Wardmedic, Malaysia) using $27 \mathrm{~F}$ primer. Nucleotide amino acid sequences were analyzed using BlastN tool, online alignment 


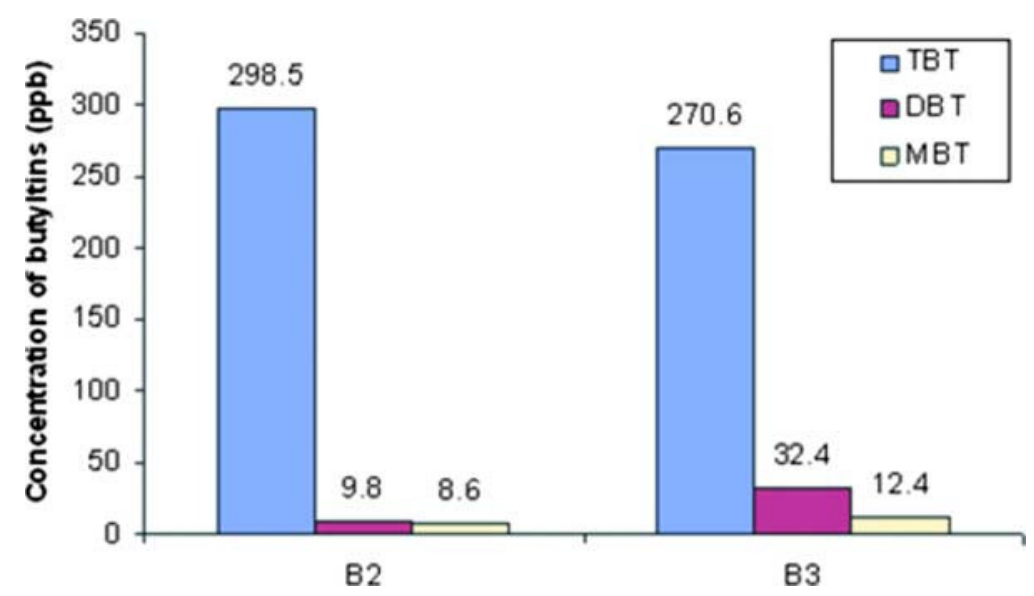

FIG. 1-Level of butyltins in samples degraded by the microorganisms (initial concentration of TBT was $325.5 \mathrm{ppb})$.

library available from the National Institute for Biotechnology Information server (http:// www.ncbi.nlm.nih.gov) giving generic name of the isolates.

\section{Results and Discussion}

Sediment from Bowling basin was highly contaminated with butyltins and TBT exceeded the Environmental Quality Standard (water, $0.0002 \mathrm{ppb}$; sediment, $0.0046 \mathrm{ppb}$ ) by magnitudes [12]. In the sediment, $153.44 \mathrm{ppb}\left(3.3 \times 10^{4} \mathrm{EQS}\right)$ of TBT was measured. In the canal water, $0.84,1.13$, and $2.16 \mathrm{ppb}$ of TBT, DBT, and MBT were found, respectively $\left(4.2 \times 10^{3}\right.$ EQS). The high organic carbon content $(12.10 \%)$ of Bowling basin's sediment led to high accumulation of butyltins. As a result of butyltin contamination, microorganisms occurring in the environment might have adapted to utilize TBT as a carbon source and/or resistance to the toxicity of TBT [13]. Therefore, isolation of TBT utilizing microorganisms from the sediment collected from Bowling Basin is a practical option.

After the subcultures, the bacteria found on the screening medium agar were isolated and restreaked to ensure their purity. The high concentration of TBT added into the glycerol medium inhibited growth or killed most of the bacteria that had low resistivity to TBT. However, the isolated microorganisms thrived when TBT exposure levels were high. Two strains of bacteria were isolated and were designated B2 and B3. These pure cultures were assumed to degrade TBT. However, the isolated bacteria might not utilize carbon from the butyl group but be resistant to high concentrations of TBT and grow with nutrients in the medium. Hence, further experiments on each microorganism were undertaken to confirm their TBTdegrading capability.

During the assay for TBT degradation, the initial concentration of TBT was $1 \mu M(325.5 \mathrm{ppb})$. After the degradation, TBT and its metabolites were detected by GC-MS. The degradation of TBT by B2 and B3 was 8.3 and $16.9 \%$, respectively. Figure 1 shows the levels of TBT and its metabolites after incubation, demonstrating that microorganisms acquired from the sediment show the potential to degrade TBT under cometabolism conditions.

By the Reed and Muench [9] method, the $\mathrm{EC}_{50}$ of $\mathrm{B} 2$ and $\mathrm{B} 3$ were 88.73 and $112.53 \mu M$, respectively. The high $\mathrm{EC}_{50}$ levels obtained suggest that the resistivity of the bacteria to TBT in water and the values in different media do vary [13]. The low $\mathrm{EC}_{50}$ indicates the greater sensitivity of the bacteria. Therefore, the resistivity level of the bacterial strain B3 was higher than that of B2 under the conditions stated. The $\mathrm{EC}_{50}$ values obtained also suggests that the level of TBT contamination in the Bowling basin (153.44 ppb equivalent to $0.47 \mu M$ ) would not cause major growth inhibition of the bacteria or suppress its activity.

The results from the biochemical test are shown in Table 1. B2 was identified as Citrobacter braakii at an identification of $99.8 \%$ confidence interval and B3 was Enterobacter cloacae at an identification of 95.1\% confidence interval. From Fig. 2, morphology tests show that the bacteria strain B2 and B3 are both short rods Gram negative bacteria which are about $0.65-\mu \mathrm{m}$ length.

The 16-s rDNA sequencing confirmed the identification of the biochemical test. The strain B2 is 
TABLE 1-Biochemical characteristics of isolated TBT degrader bacteria obtained from sediment sample using API 20E, oxidase test, and catalase test. Remark: $-v e=$ Gram negative; $+=$ positive reaction; - =negative reaction..

\begin{tabular}{|c|c|c|}
\hline \multirow[b]{2}{*}{ Characteristics } & \multicolumn{2}{|c|}{ Reaction } \\
\hline & $\mathrm{B} 2$ & B3 \\
\hline Gram's reaction & - ve & - ve \\
\hline$\beta$-galactosidase production & & \\
\hline (ortho-nitro-phenyl- $\beta$-D-galactopyranoside) & + & + \\
\hline Arginine dihydrolase production & + & + \\
\hline Lysine decarboxylase production & - & - \\
\hline Ornithine decarboxylase production & + & + \\
\hline Citrate utilization & + & + \\
\hline $\mathrm{H}_{2} \mathrm{~S}$ production & + & - \\
\hline Urease production & - & - \\
\hline Tryptophane deaminase production & - & - \\
\hline Indole production of tryptophane & - & - \\
\hline Acetoin production & - & + \\
\hline Hydrolysis of gelatin & - & - \\
\hline \multicolumn{3}{|l|}{ Fermentation or oxidation of: } \\
\hline -Glucose & + & + \\
\hline -Mannitol & + & + \\
\hline -Inositol & - & - \\
\hline -Sorbitol & + & + \\
\hline -Rhamnose & + & + \\
\hline -Sucrose & - & + \\
\hline -Melibiose & + & + \\
\hline -Amygdalin & + & + \\
\hline -Arabinose & + & + \\
\hline Cytochrome oxidase & - & - \\
\hline Catalase production & + & + \\
\hline
\end{tabular}

Citrobacter braakii (AF025368.1) at $99 \%$ identity. B3 is Enterobacter cloacae (EU733519.1) at $99 \%$ identity.

From previous reports, Citrobacter and Enterobacter were found as a TBT resistant (not degrading) bacteria [13] and Enterobacter cloacae was previous found to degrade pentaerythritol tetranitrate and 2,4,6-trinitrotoluene [14,15]. However, these two bacteria have never been studied or isolated dependent upon their TBT degrading capability. Also, their capacity to degrade TBT has never been previously studied.

\section{Conclusion}

The water and sediment samples collected from Bowling Basin were contaminated with butyltin compounds. DBT and MBT found in the samples implying that degradation at this site occurred. Isolation of TBT-degrading bacteria from the contaminated sediments collected from Bowling basin, Glasgow, was

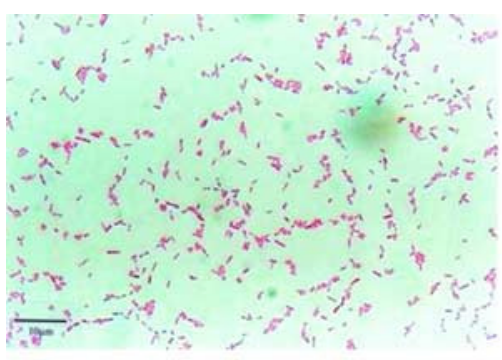

(a)

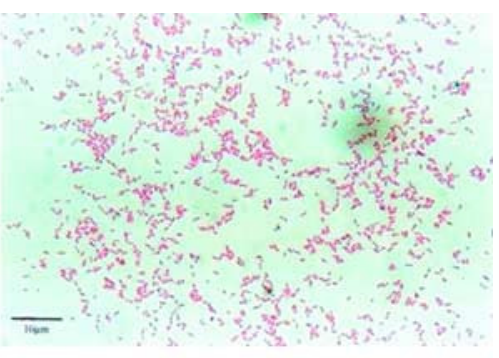

(b)

FIG. 2-Microscopic photos of the TBT degrader (a) B2 and (b) B3. 
successful. After investigation of the isolates capability, two strains of TBT degrader which contain high resistivity to TBT were found. The identification and characterization of TBT degrader indicates the two isolated bacteria are Citrobacter braakii and Enterobacter cloacae. The observed TBT degradation efficiency and resistivity under the studied conditions suggested that Enterobacter cloacae was more efficient than Citrobacter braakii. Moreover, the isolation on TBT degrading ability or the study of TBT degradation of these two bacteria has never been reported previously.

\section{Acknowledgments}

The writers would like to acknowledge Dr. Tom J. Aspray from Environmental Reclamation Services Ltd. (ERS) and Dr. Arinthip Thumchaipenet from Kasetsart University for their valuable suggestion. This work was also supported by Center of Excellence for Innovation in Chemistry (PERCH-CIC).

\section{References}

[1] United Nations, "Review of Notifications of Final Regulatory Actions to Ban or Severely Restrict a Chemical: Tributyl Tin Compounds," Rotterdam Convention on the Prior Informed Consent Procedure for Certain Hazardous Chemicals and Pesticides in International Trade Chemical Review Committee, Geneva, February, 11-18, 2005 (unpublished).

[2] Paton, G. I., Cheewasedtham, W., Marr, I. L., and Dawson, J. J. C., "Degradation and Toxicity of Phenyltin Compounds in Soil," Environ. Pollut., Vol. 144, 2006, pp. 746-751.

[3] Matthiessen, P., and Gibbs, P. E., "Critical Appraisal of the Evidence for Tributyltin-Mediated Endocrine Disruption in Mollusks," Environ. Toxicol. Chem., Vol. 17, 1998, pp. 37-43.

[4] Hoch, M., "Review: Organotin Compounds in the Environment-An Overview," Appl. Geochem., Vol. 16, 2001, pp. 719-743.

[5] UNEP. Bibliography for a Selected Number of Persistent Toxic Substances, September 2000. GEF: Regionally based assessment of persistent toxic substances.

[6] Dowson, P. H., Bubb, J. M., and Lester, J. N., "Persistence and Degradation Pathways of Tributyltin in Freshwater and Estuarine Sediments," Estuar. Coast. Shelf Sci., Vol. 42, 1996, pp. 551-562.

[7] Bangkedphol, S., Keenan, H. E., Davidson, C., Sakultantimetha, A., and Songsasen, A., "Development of a Low-Cost Method of Analysis for the Qualitative and Quantitative Analysis of Butyltins in Environmental Samples," J. Environ. Sci. Health, Part A, Vol. 43, 2008, pp. 1744-1751.

[8] ASTM Standard D2974-87, "Standard Test Methods for Moisture, Ash, and Organic Matter of Peat and Other Organic Soils," Annual Book of ASTM Standards, ASTM International, West Conshohocken, PA, 2000.

[9] Reed, L. J., and Muench, H., "A Simple Method of Estimating Fifty Percent Endpoints," Am. J. Hyg., Vol. 27, 1938, pp. 493-497.

[10] Krieg, N. R., and Holt, J. G., Bergey's Manual of Systematic Bacteriology, Williams \& Wilkins Co., Baltimore, 1984, Vol. 1.

[11] Sambrook, J., and Russel, D. W., Molecular Cloning: A Laboratory Manual, Cold Spring Habor Laboratory, New York, 2001.

[12] "Environmental Quality Standards (EQS) Substance Data Sheet: Tributyltin Compounds (TBT-ion)," Proceedings of the Common Implementation Strategy for the Water Framework Directive, Brussel, January 15, 2005 (unpublished).

[13] Wuertz, S., Miller, C. E., Pfister, R. M., and Cooney, J. J., "Tributyltin-Resistant Bacteria from Estuarine and Freshwater Sediments," Appl. Environ. Microbiol., Vol. 57, 1991, pp. 2783-2789.

[14] Binks, P. R., French, C. E., Nicklin, S., and Bruce, N. C., "Degradation of Pentaerythritol Tetranitrate by Enterobacter cloacae PB2," Appl. Environ. Microbiol., Vol. 62, 1996, pp. 1214-1219.

[15] French, C. E., Nicklin, S., and Bruce, N. C., "Aerobic Degradation of 2,4,6-Trinitrotoluene by Enterobacter cloacae PB2 and by Pentaerythritol Tetranitrate Reductase," Appl. Environ. Microbiol., Vol. 64, 1998, pp. 2864-2868. 